\title{
PHONETIC PECULIARITIES OF THE FRENCH LANGUAGE OF CAMEROON
}

\author{
Yuliya S. Blazhevich \\ Belgorod National Research University, Belgorod, Russia
}

\begin{abstract}
Phonetic peculiarities of the territorial variant of the French language in Cameroon have been considered in the article. Audio- and video recordings of French-speaking Cameroonians have been used for the study. Significant divergences between the phonetic systems of the French language of the former metropolis and its Cameroonian version have been detected in the systems of vowels and consonants as well as on the prosodic level. The analysis proves that local Cameroonian languages being L1 of the speakers interfere with the French language of Cameroon as articulation habits of mother tongues are transferred into their speech in the French language. In the vowel system we have detected the following phonological phenomena: substitution of French sounds by the L1 ones, denasalization, diphthongization of vowels, change of sound length and use of epenthesis. In the consonant system such phenomena as substitution, devoicing, voicing, palatalization, sound opposition attenuation and consonant cluster simplification have been detected. Alterations are also observed on the prosodic level where L1 interference manifests in the form of excess tone marking transferred into French which is characteristic of most indigenous African languages. Four groups of accents spoken in Cameroon are also singled out and their main characteristics are described in the article.

Key words: French language, phonetics, phonetic processes, interference, accents, Cameroon.

Citation. Blazhevich Yu.S. Phonetic Peculiarities of the French Language of Cameroon. Vestnik Volgogradskogo gosudarstvennogo universiteta. Seriya 2. Yazykoznanie [Science Journal of Volgograd State University. Linguistics], 2019, vol. 18, no. 4, pp. 221-230. (in Russian). DOI: https://doi.org/10.15688/jvolsu2.2019.4.17

УДК 811.133.1’342

Дата поступления статьи: 24.12.2018

ББК $81.471 .1-1$

Дата принятия статьи: 03.07.2019
\end{abstract}

\section{ФОНЕТИЧЕСКИЕ ОСОБЕННОСТИ ФРАНЦУЗСКОГО ЯЗЫКА КАМЕРУНА}

\author{
Юлия Сергеевна Блажевич \\ Белгородский национальный исследовательский университет, г. Белгород, Россия
}

\begin{abstract}
Аннотация. В исследовании описаны фонетические особенности территориального варианта французского языка Камеруна. Материалом для анализа послужили аудио- и видеозаписи живой речи франкофонных камерунцев. Выявлены существенные различия между фонетической системой французского языка бывшей метрополии и камерунского варианта французского языка. Они установлены в вокализме, консонантизме, тоне и фонотактике ударения. В результате проведенного анализа доказано существование значительной интерференции со стороны этнических языков Камеруна, когда произносительные привычки родного языка говорящего переносятся в его речь на французском языке. В системе вокализма охарактеризованы такие явления, как субституция звуков французского языка звуками родных языков камерунцев, деназализация, дифтонгизация гласных, изменение их долготы, широкое использование гласных эпентез (анаптиксис и протеза).

ح В системе консонантизма зафиксированы субституция звуков, оглушение, озвончение, палатализация, а также ㄱ. процессы ослабления некоторых оппозиций звуков и упрощение кластеров согласных. На суперсегментном ; уровне также обнаружено влияние на французский язык местных тональных языков. В статье выявлены четыре группы акцентов регионов Камеруна и описаны наиболее характерные черты каждого из них.

Ключевые слова: французский язык, фонетика, фонетические процессы, интерференция, акцент, Камерун.

Цитирование. Блажевич Ю. С. Фонетические особенности французского языка Камеруна // Вестник Волгоградского государственного университета. Серия 2, Языкознание. - 2019. - Т. 18, № 4. - С. 221-230. DOI: https://doi.org/10.15688/jvolsu2.2019.4.17
\end{abstract}




\section{Введение}

Актуальность данного исследования обусловлена необходимостью изучения изменений, происходящих во французском языке (далее - ФЯ) вне пределов исконных территорий его распространения. Французский язык в Африке имеет свою специфику по сравнению с языком бывшей метрополии. Эта специфика проявляется на всех языковых уровнях, в том числе и на фонетическом, где африканизмы, по словам А.И. Чередниченко, «представляют собой исторически сложившуюся совокупность признаков, характеризующих этот ареал как в целом, так и по отдельным его зонам» [Чередниченко, 1983, с. 73]. Цель нашего исследования - описание фонетических особенностей ФЯ Камеруна, являющихся результатом влияния местных языков. Для этого ставятся следующие задачи: выявить результаты и определить специфику интерференции во ФЯ Камеруна на фонологическом уровне; установить лингвистические и экстралингвистические факторы, влияющие на языковые изменения, связанные с интерференцией. Для решения данных задач применялся метод сопоставительного типологического анализа, характерного для исследований в области контактной лингвистики.

Материалом для анализа послужили аудио- и видеозаписи живой речи франкофонных камерунцев, включая записи радио- и телепередач. Общий объем звучащего материала -6 часов.

\section{Фонетический инвентарь}

Системы гласных, согласных и просодические характеристики ФЯ Камеруна отличаются от ФЯ бывшей метрополии.

Фонетическая система ФЯ включает 17 согласных, 3 полугласных и 16 гласных.

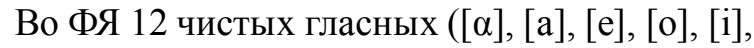
$[\mathrm{u}],[\mathrm{y}],[œ],[\varnothing],[\varepsilon],[ə],[ə])$ и 4 носовых ([ã],

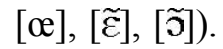

Система согласных (и полугласных) состоит из следующих фонем: [p], [b], [t], [d], $[\mathrm{k}],[\mathrm{g}],[\mathrm{m}],[\mathrm{n}],[\mathrm{n}],[\mathrm{f}],[\mathrm{v}],[\mathrm{s}],[\mathrm{z}],[\mathrm{l}],[\mathrm{r}],[\mathrm{j}]$, $[\mathrm{f}],[3],[\mathrm{w}],[\mathrm{u}]$.
Фонетическая система камерунского варианта ФЯ обладает некоторыми отличиями от языка бывшей метрополии. Так, во ФЯ Камеруна, помимо 17 согласных и 3 полугласных, есть дополнительные фонемы: [h], [?] («гортанная смычка»- фр. «соup de glotte», анг. «glottal stop») и [р]. Вокализм состоит из 11 гласных: [a], [е], [о], [i], [u], [у], [œ], [ø], [ع],

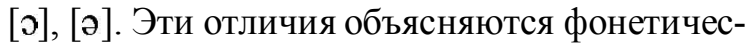
кой интерференцией. Для большинства камерунцев ФЯ выступает вторым (третьим) или даже иностранным языком, на который переносится артикуляционная база того или иного этнического языка. Влияние родного языка говорящего на фонетическом уровне проявляется в возникновении «дифференциальных признаков», которые, как правило, характерны для речи всего билингвального (или мультилингвального) коллектива. Как показано А.И. Чередниченко, количество таких признаков может зависеть от «степени индивидуального овладения орфоэпическим стандартом, образовательного уровня говорящих, традиций семейного или социально-бытового говорения, а также в определенной мере - от особенностей слухового и речедвигательного аппарата» [Чередниченко, 1983, с. 73].

При рассмотрении фонетических особенностей ФЯ, характерных для многих франкоязычных камерунцев (или многочисленных групп), мы учитываем отсутствие единого варианта произношения.

\section{Особенности вокализма}

Наличие большого количества гласных выступает одной из причин «неустойчивости французского вокализма, выхода из употребления некоторых звуков, стирания фонологических различий между существующими оппозициями» [Багана, Трещева, 2012, с. 51].

На фонетическом уровне влияние этнических языков на ФЯ проявляется в стирании различия между чистыми гласными. Например, фонетические системы большинства языков банту (на них говорит более 60 \% населения Камеруна) имеют систему из 5 гласных: [i], [е], [а], [о], [u], а язык эвондо (яунде), тоже входящий в банту, - из 7 гласных: [i], [e], $[\varepsilon],[\mathrm{a}],[\circ],[\mathrm{o}],[\mathrm{u}]$. Это значительно меньше, чем во ФЯ. 
В том случае, если в родном языке говорящего не существует соответствующих звуков, происходит субституция одним из звуков родного языка. Перечислим характерные замены.

Замена [y] на [i] наблюдается в речи носителей языков мунданг, дбага, баса, фула и др. Например:

obtenu прич. «полученный» [obtəny] произносится как [optəni], как [di].

$d \hat{u}$ прил. «должный, надлежащий» [dy]-

Замена $[\mathbf{y}] /[\mathbf{y}]$ на $[\mathbf{u}]$ характерна для носителей языка фула (фульбе, фульфульде). Например:

muet прил. «молчаливый, беззвучный» [mчє] заменяется на [mue],

juger гл. «судить, осуждать» [зузе] произносится как [зизе].

Замена [ø] на [е] происходит в речи представителей народности бети-фанг: они часто смешивают данные звуки в начале слова, что иногда приводит к орфографическим ошибкам, например:

вместо Eustache сущ. имя собств. «Юстас» - Estache,

вместо européens сущ. «европейцы»-les éropéens,

вместо géometrie euclidienne сущ. + прил. «евклидова геометрия» - géometrie éclidienne (примеры приводятся по: [ZangZang, 1991,p. 120]).

Замена [ә] на [е] характерна для носителей фула и баса, поскольку в их родных языках фонема [ә] отсутствует. Например:

regarder гл. «смотреть» [вәgабde] произносится как [regarde].

Замена $[\varepsilon]$ на [е] возможна в речи носителей языка фула. В нем не существует гласного $[\varepsilon]$, поэтому в речи на ФЯ он также отсутствует. Например: [ave],

avait ф. гл. «иметь» [ave] произносят как

savait ф. гл. «знать» [save] - как [save].

Замена [э] на [o] характерна для народностей фульбе, эвондо (яунде) и мунданг. Интересно, что открытого гласного не наблюдается даже перед согласными [j], [3], [s], [z], [f], [v], [t], [d], как это происходит во ФЯ языке бывшей метрополии. Например:

ordre сущ. «порядок» [эьdь] произносится как [ordr], poche сущ. «карман, сумка» [рој] - как [pol, polə], mole сущ. «моль, родинка» [mol, mole] как [mol, mole].

Замена [р] на дифтонг [iә] - довольно редкое явление, наблюдаемое у представителей народности фульбе, например:

d'abord нареч. «сначала» [dabo:s] произносится как [dabiə],

école сущ. «школа» [ekol] - как [ekiəl].

Замена $[\mathbf{r}]$ на гласный звук сопровождается дифтонгизацией. Она происходит в речи говорящих на грассфилдских языках банту и фула. Например:

garder гл. «хранить» [gaьde] произносится как [gaəde],

vert прил. «зеленый» [vєь] - как [vєə].

Для ФЯ Камеруна характерны такие фонетические явления, как эпентеза, а именно, анаптиксис (добавление гласного звука между двумя согласными) и протеза (добавление вторичной гласной в начале слова). Вставка звука помогает говорящим подстраивать произношение слов на неродном языке под свои произносительные привычки. По этой причине может происходить добавление [ә] там, где его изначально быть не должно:

- в начале слова перед согласным (характерно для говорящих на языке гомала), например:

s'entendre гл. «ладить, уживаться друг с другом» [sãtãds] произносится как [əsãntãndrə],

l'oncle сущ. «дядя» [lõkl] - как [əlЈ̣̃kl];

- в середине слова на стыках двух слогов с согласными -tn-, -rg-, -rl-, -rv-, -rm- и др., например:

pourquoi нареч. «зачем» [pu:rkwa] произносится как [purekwa],

ethnie сущ. «этнос» [ctni] - как [ctəni];

- в конце слова, например:

réfléchir гл. «размышлять» [вefle]ік] произносится как [refle $[\mathrm{ir} ə]$,

mil числ. «тысяча» [mil] - как [milə].

Гласный [ə] добавляется и к корню некоторых глаголов 1-й группы, оканчивающихся на гласный звук при спряжении в будущем времени и условном наклонении, а также к некоторым другим словам, в которых во ФЯ этот звук выпадает [Djoum Nkwescheu, 2008, p. 185], например: 
saluera ф. гл. «приветствовать» [salчва] произносится как [saluəra], [puəra], puera ф. гл. «смердеть» [рцьа] - как épieront ф. гл. «подстерегать, караулить» [ерікว̃] - как [ерjərว̃y], maniement сущ. «обращение» [manimã] как [manjəmãy].

Гласный [ә] во ФЯ Камеруна в принципе никогда не исчезает, в отличие от ФЯ метрополии, например:

multilingue прил. «многоязычный»

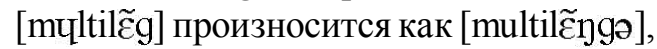

jeter гл. «бросать» [з[ə] te] - как [зəte], pétanque сущ. «петанк» [petãk] - как [petãykə].

Особенностью ФЯ Камеруна является частичная или полная деназализаџия гласного звука, который предшествует носовому согласному. Полная деназализация [a] и [o] peгистрируется перед носовым губно-губным [m], например:

tromper гл. «ошибаться» [tьว̃ре] читается как [trəmpe],

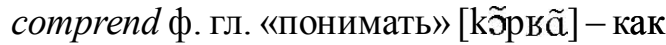
[koprãy],

laтре сущ. «лампа» [1ãp] - как [lampə].

В остальных случаях происходит частичная деназализация.

Как объясняет Ж. Багана, исследовавший конголесские языки, «частичная или полная потеря носового признака может быть обусловлена и влиянием местных языков, лишенных подобного явления. Однако необходимо отметить, что, хотя деназализация и свойственна лишь некоторым социальным слоям населения, она представляет собой реальную угрозу чистоте ФЯ» [Багана, Трещева, 2012, с. 53].

Зафиксированные изменения в системе вокализма ФЯ Камеруна можно отнести к проявлению интерференции со стороны местных камерунских языков.

\section{Особенности консонантизма}

Система согласных ФЯ характеризуется как относительно стабильная, однако нами выявлены колебания ее реализации в потоке живой речи.

Фонемы [r] и [I]. Увулярный звук [R] (или [г]) сложен для произношения африкан- цев, и поэтому в речи большинства из них доминирует апикальный [r] (за исключением жителей Северного Камеруна, которые его чрезмерно грассируют). По мнению Ж. Багана, это явление имеет несколько причин: «с одной стороны, это объясняется спецификой собственно африканской артикуляционной базы, а с другой - желанием некоторых африканцев таким особым произношением подчеркнуть свою национальную принадлежность. $\mathrm{B}$ целом изменения в произношении $[\mathrm{r}]$ носят чисто фонетический характер и не затрагивают фонологического статуса этой фонемы в системе согласных» [Багана, Трещева, 2012, c. 52]. Например:

regarder гл. «смотреть» [вәgавdе] произносится как [regarde].

Иногда [r] выпадает из-за сложности произношения, а также может наблюдаться еще большее удлинение предшествующей гласной, например:

pour предл. «для, в, на» [pu: ь] произносится как [pu:],

porquoi нареч. «зачем» [pu: skwa] - как [pu: kwa].

Иногда, наоборот, гласный становится кратким:

pour предл. «для, в, на» [pu: в] произносится как [рu],

parce que нареч. «потому что» [pa: Бsəkə] как [paskə].

Недостаточная дифференциачия [r] и [1] является еще одной особенностью ФЯ Камеруна. Почти во всех грассфилдских языках банту Западного Камеруна нет звука [r], а соответственно, отсутствует оппозиция между звуками [r] и [1]. В речи на ФЯ можно наблюдать замену [r] на [1] или же [1] на [r], например:

crient ф. гл. «кричать» [kri] может произноситься как [kli],

pluriel прил. «множественный» [plyrjel] как [prurjel] (явление сверхдифференциации) (см. подробнее: [Zang Zang, 1999, p. 117]).

У представителей некоторых народностей Камеруна при артикуляции на ФЯ наблюдается замена $[\mathrm{r}]$ на взрывные велярные $[\mathrm{k}]$ и [g]. Кроме того, у носителей языков хауса, фула, группы языков гбе и манден возможна замена $[\mathrm{r}]$ на специфический звук $[\mathrm{\gamma}]$. Это звонкий велярный спирант, звучание которого 
представляет собой что-то среднее между [ð] и [g]. Приведем несколько примеров вышеописанных замен:

marche ф. гл. «идти» [mа:в ] произносится как [makjə], sortir ф. гл. «выходить» [sə:sti:к] - как [sokti],

faire гл. «делать» $[\mathrm{f} \varepsilon: \mathrm{b}]$ - как [fєəg], perde ф. гл. «терять» [рєь:d] - как [рєəgə], normal прил. «нормальный» [nə:smal] как [noymal],

universitaire прил. «университетский»

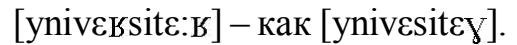

Фонемы [b] и [d]. Как известно, французский вариант реализации фонем [b] и [d] предполагает выход воздуха, однако в языках банту данные фонемы произносятся как имплозивные (то есть со вдохом) и графически могут быть обозначены как [b] и [d]. Поэтому среди говорящих на языках банту может наблюдаться фонетическая интерференция во ФЯ, при которой [b] и [d] заменяются на [b] и [d] соответственно, например:

beau прил. «красивый» [bo] произносится как [Бо],

bosser гл. «вкалывать, работать» [bose] - как [bose],

donner гл. «давать» [done] - как [done].

Оппозиции $[\mathbf{d}] /[\mathbf{d z}]$ и $[\mathbf{t}] /[\mathbf{t s}]$. Варианты [dz], [ts] характерны, по данным Э. Билоа, для говорящих на языке тупури в Северном Камеруне [Biloa, 2004, p. 98-99]. Этот процесс связан с ассибиляиией (или палатализацией) согласных под действием гласных переднего ряда, например:

tunnel сущ. «тоннель» [tynel] произносится как [tsuncl], tigre сущ. «тигр» [tigь] - как [tsigre], talisman сущ. «талисман» [talismã] - как [tsalismã],

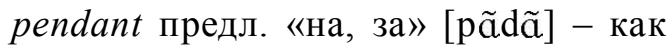
[pãdzã],

duper гл. «обмануть, одурачить» [dype] как [dzupe].

Оппозиции [s]/[z] и []]/[3]. В некоторых языках банту фонема [s] сопровождается звуком [i] и, слегка палатализуясь, произносится почти как [j], поэтому иногда эта особенность проявляется и во ФЯ Камеруна, например: cinéma сущ. «кино» произносится как [shinema].
Может происходить и обратная замена, когда шипящие согласные [ई] и [3] произносятся как свистящие [s] и [z] соответственно, что наблюдается в речи представителей некоторых народностей Северного региона. В их языках соответствующие звуки отсутствуют, например:

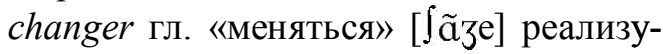
ется как [sanze].

Для речи на ФЯ в Камеруне характерно оглушение согласного [3] в начале и конце слова с заменой на [ई], например:

је мест. «я» [зә] произносится как [ $[\mathrm{e}]$, village сущ. «деревня» [vilaz] - как [vila ], jugement сущ. «суждение» [зузта̃] - как [ $\int$ yzman].

Оппозиции $[k] /[g]$ и [t]/[d]. Для языков банту характерно ослабление контраста между данными группами фонем, что может приводить к взаимозамене звуков:

magasin сущ. «магазин» [magazẽ] произносится [makaz $\widetilde{n}]$,

guitare сущ. «гитара» [gitaь] - как [gidar].

Для ФЯ Камеруна характерно упроще ние согласных кластеров посредством усечения или гласных эпентез, что объясняется спецификой слогового стереотипа, определяющей способы структурирования слога и слоговой последовательности в языках камерунцев. Поскольку такие стыки согласных нехарактерны для их этнических языков, стереотип слогоделения срабатывает и во ФЯ. Приведем несколько примеров:

[t]: exacte прил. «точный» [Egzakt] произносится как [zzat],

[s]: existe ф. гл. «существовать» [Egzist] как [ezit], [mãy],

$[\mathrm{k}]:$ manque ф. гл. «скучать» $[\mathrm{mãk}]-$ как

[g]: langue сущ. «язык» [lãg] как [lã̃],

[1]: capable прил. «способный» [kapabl] как [kapab],

[r]: subvenir гл. «приходить на помощь» [sybvəni:r] - как [syvəni:].

Мы уже отмечали, что во ФЯ Камеруна существуют дополнительные фонемы. Это [h] и [?] («гортанная смычка», или «твердый приступ»). Одной из причин их возникновения является хиатус, поскольку две гласные подряд также противоречат произносительным привычкам местного населения, например: 


\section{МАТЕРИАЛЫ И СООБЩЕНИЯ}

- один гласный среднего ряда, а другой заднего:

coaguler гл. «коагулировать» [kəagyle] может произноситься как [kohagyle] или как [ko?agyle],

coasser гл. «квакать»[kəase] - как [kohase] или как [ko?ase];

- один гласный переднего ряда, а другой - заднего:

coefficient сущ. «коэффициент» [kəefisjã] произносится как [kohefisjãy] или как [ko?efisjãy].

Если же оба гласных относятся к заднему или среднему ряду, то между ними вставляют [j], например:

réalisation сущ. «реализация» [веalizasjō] произносится как [rejalizasjত̃̃] (см. подробнее: [Djoum Nkwescheu, 2008, p. 182]).

Перечисленные особенности в области консонантизма свидетельствуют о том, что произносительные привычки камерунцев переносятся в речь на французском языке. Это подтверждает наличие значительной интерференции со стороны этнических языков.

\section{Особенности суперсегментных единиц}

Тон и ударение. Различия между ФЯ в бывшей метрополии и Камеруне наблюдаются в тоне и фонотактике ударения. Во ФЯ есть 3 типа ударений: ритмическое, логическое и эмфатическое. Ритмическое ударение в большинстве камерунских языков отличается от французского, так как они относятся к тональному типу языков. Их изучению посвящены работы Л.З. Совы, которая установила, что в этих языках фонологически значимые тоны позволяют различать лексические и(или) грамматические значения: «...в языках банту тон служит средством смыслоразличительных оппозиций, однако, место таких оппозиций в структуре различных языков не одинаковое. Значимость тона для установления грамматических противопоставлений отмечается повсеместно: в частности, тон релевантен при спецификации форм глагольного спряжения, особенно при фиксации типов глагольного действия и образования прошедших времен. Значительно реже регистрируется роль тона при установлении минимальных лексических пар» [Сова, 1996, с. 33]. В качестве до- казательства Л.3. Сова приводит следующие примеры: на языке дуала à màbòlà означает «он делает», а à mabòlà - «он сделал»; mbá «я» - mba «туман» - ḿbá «насморк»; mongò «копье» - móngò «твой» - mongo «спина»; sóngo «твой отец»-songo «могила» и т. п. [Сова, 1996, с. 33].

Фонетически высказывание на местных камерунских языках зачастую представляет собой череду открытых слогов, каждый из которых принимает свой тон. Закрытые слоги встречаются редко, чаще всего это слогообразующие назальные, стоящие в начале или середине слова. Словообразующие гласные имеют тон, иногда тоном могут обладать и слогообразующие согласные. Как уже показала Л.З. Сова, «правила корреляции тона, ударения, долготы и степени открытости гласных варьируются от языка к языку и определяются спецификой артикуляции каждого речевого коллектива» [Сова, 1996, c. 33]. В начале, середине и конце предложения одно и то же слово может произноситься по-разному. Тоновые контуры утвердительных, отрицательных, вопросительных и побудительных предложений также отличаются друг от друга. Л.З. Сова отмечает, что «обычно регистрируют минимум три тона: высокий, средний и низкий. Иногда различают также средне-высокий, средне-низкий, восходящий и нисходящий тоны» [Сова, 1996, c. 31]. В языке дуала, например, различаются 5 типов тона: низкий (à), средний $(-)$, высокий (á), восходящий (ă) и нисходящий (â) [Сова, 1996, с. 31].

Фраза на языке банту, таким образом, дробится сильнее, чем соответствующая фраза на французском. Соответственно, по привычке говорящий также вносит в свою речь на ФЯ дополнительные тоны, отчего фраза кажется «рубленой». Французский язык относится к группе нетональных языков. Мелодические противопоставления в речи на таких языках не имеют закрепленных за ними семантических или грамматических значений, а способны выражать лишь некоторые общие смыслы. В то время как во ФЯ голосом выделяется отдельная смысловая группа, в камерунском варианте во фразе акцентируется каждое слово, внутри слова может акцентироваться каждый слог. 
Фонологию ФЯ Камеруна характеризуют следующие виды тона: низкий «"», высокий «'», средний «'», нисходящий «’» и восходящий «`», например:

(в слове) malheuresement [maløьøz'mã] [màlø̀vòzò̀ mã̃y],

(во фразе) Je m'en vais demain

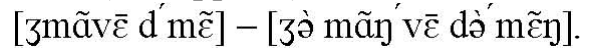

Таким образом, во ФЯ Камеруна отмечается тенденция к тональному ударению в результате переноса особенностей формирования ритма из этнических языков.

Явление liaison. Одной из отличительных черт фонологии ФЯ является фонетическое слияние слов в потоке речи (liaison). Оно происходит между двумя словами внутри ритмической группы, если первое слово заканчивается на непроизносимый согласный, а второе начинается на гласный или немое $h$. Два слова должны сливаться и звучать как одно, при этом конечный согласный первого слова также произносится. Во ФЯ Камеруна на месте связки конечный согласный первого слова как бы отрывается и присоединяется к следующему слову, мелодика речи становится отрывистой там, где должна была бы иметь плавный переход, например:

vos enfants «ваши дети» [vozãfã] произносят как [vó zãyfãy],

je suis allé «я поехал» [зә 'suizale] - как [3ə’`sŭ zàlē].

Приведенные примеры демонстрируют, что в фонотактике ФЯ Камеруна четко прослеживается «наложение» слогового стереотипа тональных камерунских языков.

\section{Территориальное распределение фонетических особенностей французского языка в Камеруне}

Подмена неизвестных звуков и непривычных сочетаний звуков иностранного языка звуками или их сочетаниями из родного языка традиционно определяется в лингвистике как акцент. Поскольку определенные иноязычные акценты на неродном языке (в данном случае французском) являются стабильными и характеризуют речь конкретных языковых коллективов, можно говорить о существовании региональных акцентов ФЯ Камеруна.
Опираясь на работы исследователей, изучавших языки Камеруна [Biloa, 2004; 2011; Djoum Nkwescheu, 2000; Fosso, 2004; Mendo Ze, 1990; Zang Zang, 1991; 1998; 1999; и др.], можно выделить 4 основных акцента во ФЯ, но и они не охватывают всего существующего разнообразия. По мнению К. де Фераль и В. Фесси, деление на акценты весьма «условно» и выражает стереотипное представление о народах Камеруна [Féral de, 1991, p. 65-66; Feussi, 2006, p. 239].

Акцент Северного региона (влияние языка фульфульде). Для жителей Северного региона характерна беглая речь и напряженное произношение звуков. Данный акцент можно узнать по чрезмерно грассированному [r], например: [il montrrre].

Большинство согласных звуков, как отмечает Дж. Мендо Зе, артикулируются в задней части ротовой полости [Mendo Ze, 1990, p. 80]. В этом регионе в родных языках местных жителей отсутствуют некоторые фонемы, что отражается на произносительных особенностях во ФЯ. Так, шипящие согласные [j] и [3] заменяются на свистящие [s] и [z], например:

chercheur сущ. «искатель» $\left[\int_{\varepsilon Б}[œ \mathrm{~L}]\right.$ произносится как [sєБsєь].

Огубленные гласные переднего ряда заменяются на неогубленные. Так, [œ], [ø], [ә] произносятся как $[\varepsilon],[\mathrm{e}],[\mathrm{e}]$ соответственно, например:

fleur сущ. «цветок» [flœк] произносится как [fles],

demeurer гл. «оставаться» [dәтюве] как [dетеве].

Носители языков фула или фульфульде (племена фульбе) заменяют [ع] на [е]: [avek],

avec предл. «c» [avek] произносится как

même част. «даже, хоть» $[\mathrm{m \varepsilon m}]-$ как [mem].

Звук [э] заменяется на [о], например:

е́роquе сущ. «эпоха» [epok] произносят как [epok].

Акценты Южного и Центрального регионов (влияние языков бети и булу). В Южном и Центральном регионах Камеруна среди народностей бети-фанг и булу существуют 2 акцента. 
Речь представителей эвондо (яунде), по образному определению Дж. Мендо Зе, «нетороплива, мелодична и немного женственна» [Mendo Ze, 1990, p. 81-82]. Характерной ее чертой является огубление согласных перед звуком [o], например:

comme нареч. «как» $[\mathrm{kom}]$ произносится как [kwəm],

il sort личн. мест. + гл. «он выходит» [il sэь] - как [il swor].

Гласных звуков [у], [ø] и [œ] не существует, поэтому их часто заменяют на огубленные гласные заднего ряда [i], [e], [ع]:

mиsique сущ. «музыка» [myzik] произносят как [mizik],

plume сущ. «перо» [plym] - как [plim].

Среди говорящих на булу $[\varepsilon]$ произносится как [е], например:

parlait ф. гл. «говорить» [равlє] звучит как [parle].

Подробно об особенностях речи на французском носителей указанных языков см.: [Mendo Ze, 1990].

Акцент Западного региона (влияние языков бамилеке). Во ФЯ большинство согласных образуются в передней части ротовой полости, в то время как в языках бамилеке - в задней. Поэтому носители языка гомала испытывают сложности в произношении переднеязычных звуков [1], [r], [n], которые имеют неустойчивый характер. Так, [1] может опускаться, например:

Il n'est pas mon ami «Он не мой друг» произносится как [inepamønami].

На стыке со взрывными согласными [r] может выпадать или заменяться другим звуком, например:

Il porte личн. мест. + гл. «Он несет» может произноситься как [ipot], [ipэ:tə], [ipokt], [ipogt], [ipo?t].

В Западном регионе в некоторых диалектах языка бамилеке отсутствует фонема $[\mathrm{r}]$ :

litre сущ. «литр» [lits] произносят как [litle], arbitre сущ. «арбитр» [авbits] - как [albitl] (см.: [Zang Zang, 1999, p. 117]).

Для народности бамилеке характерно также добавление [ә] после носовых гласных там, где их не должно быть, например:

il plonge «он ныряет» [il pl כ̋] произносится как [iplฮ̃зə], concept сущ. «понятие» [kכ̃sєpt] - как [kכ̃s\&ptə].

Акцент Прибрежного региона (влияние языка баса). Акцент баса Центрального и Прибрежного регионов можно определить по отсутствию гласных [œ], [ø], [о] и [у] (их нет в языке баса).

Говорящие заменяют [у] на [u] или [i]: $t u$ мест. «ты» может звучать как [tu] или [ti].

Звуки [ø], [ə], [о] заменяются на [е], [e], [o] соответственно, например:

milieu сущ. «среда» [miljø] произносится как [milje],

deux сущ. «два» [dø] - как [de],

miеих нареч. «лучше» [mјø] - как [mје];

que союз. «что» $[\mathrm{kə}]$ - как [ke],

demander гл. «спрашивать» [dəmãde] как [dəmãyde],

се мест. «это» [sə] - как [se],

méthode сущ. «метод» [metod] - как [metod] (подробно см.: [Mendo Ze, 1990, p. 82]).

\section{Выводы}

Отклонения фонологической системы камерунского варианта ФЯ от ФЯ в бывшей метрополии происходят в результате ее приспособления к фонологической системе автохтонных языков. О данном виде контактно обусловленных изменений свидетельствует появление новых звуков, а также исчезновение или неправильная реализация существующих фонем. Звуковой строй камерунских языков как бы накладывается на фонетическую систему ФЯ, в результате чего формируется особый тип территориального варианта произношения. Влияние местных языков на ФЯ в Камеруне обнаруживается в особенностях, которые характеризуют суперсегментный уровень. Поскольку большинство камерунских языков относится к тональному типу, говорящие добавляют в свою речь дополнительные тоны и ударения, несвойственные просодической организации высказываний на ФЯ. Комбинации выявленных особенностей формируют во французском языке Камеруна разнообразие акцентов в зависимости от территории и языка автохтона. 


\section{СПИСОК ЛИТЕРАТУРЫ}

Багана Ж., Трещева Н. В., 2012. Фонетическая манифестация в условиях франко-африканского билингвизма // Научные ведомости Белгородского государственного университета. Серия: Гуманитарные науки. № 12 (131), вып. 14. С. 51-54.

Сова Л. 3., 1996. У истоков языка и мышления. Генезис африканских языков. СПб. : Лабрис. $384 \mathrm{c}$.

Чередниченко А. И., 1983. Язык и общество в развивающихся странах Африки. Киев : Изд-во Киев. ун-та. 165 с.

Biloa E., 2004. Le phonetisme du français oral en milieu tupuri an Nord Cameroun // Africa Meets Europe: Language Contact in West Africa / ed. by G. Echu, S. Gyasi Obeng. N. Y. : Nova Science Publ. P. 89-102.

Biloa E., 2011. Le français parlé et écrit en Afrique : Bilan et perspectives. Saarbrucken : Editions universiataires europeennes. $532 \mathrm{p}$.

Djoum Nkwescheu A., 2000. Aspects prosodiques et phonématiques du français parlé au Cameroun. Grenoble : Université de Grenoble III-Stendhal. $530 \mathrm{p}$.

Djoum Nkwescheu A., 2008. Les tendances fédératrices des déviations du Français camerounais de l'identité des processus linguistiques dans les changements diachroniques et géographiques // Le français en Afrique. № 23. P. 167-198.

Féral de C., 1991. Norme endogène du français au Cameroun // Bulletin du Centre d'étude des plurilinguismes. № 12. P. 65-71.

Feussi V., 2006. Une construction du français à DoualaCameroun. Tours : Université François Rabelais de Tours. $717 \mathrm{p}$.

Fosso C. de F., 2004. Dynamique du français au Cameroun: problèmes sociolinguistiques et stylistiques, enjeux didactiques et glottopolitiques. Yaoundé : Presses universitaires d'Afrique. $270 \mathrm{p}$.

Mendo Ze G., 1990. Une crise dans les crises. Le français en Afrique noire camerounais où chaque groupe linguistique tient à son identité, l'État francophone. Le cas du Cameroun. P. : ABC. $380 \mathrm{p}$.

Zang Zang P., 1991. Le processus de dialectalisation du français en Afrique noire: le cas du Cameroun. Yaoundé : Université de Yaoundé I. 450 p.

Zang Zang P., 1998. Le français en Afrique: normes, tendances évolutives, dialectisation. Munchen : Lincom Europa. 452 p.

Zang Zang P., 1999. Le phonétisme du français camerounais // Le français langue africaine / ed. by Mendo Ze. P. : Publisud. P. 112-129.

\section{REFERENCES}

Baghana J., Treshcheva N.V., 2012. Foneticheskaya manifestatsiya $\mathrm{v}$ usloviyakh franko-afrikanskogo bilingvizma [Phonetic Manifestation in Bilingual Situation]. Nauchnye vedomosti Belgorodskogo gosudarstvennogo universiteta. Seriya: Gumanitarnye nauki [Belgorod State University Scientific Bulletin. Series: Humanities], no. 12 (131), iss. 14, pp. 51-54.

Sova L.Z., 1996. Uistokov yazyka i myshleniya. Genezis afrikanskikh yazykov [At the Origins of Language and Mind. Genesis of African Languages]. Saint Petersburg, Labris Publ. 384 p.

Cherednichenko A.I., 1983. Yazyk $i$ obshchestvo $v$ razvivayushchikhsya stranakh Afriki [Language and Society in the Developing Countries of Africa]. Kiev, Izd-vo Kievskogo universiteta. $165 \mathrm{p}$.

Biloa E., 2004. Le phonetisme du français oral en milieu tupuri an Nord Cameroun. Echu G., Gyasi Obeng S., eds. Africa Meets Europe: Language Contact in West Africa. New York, Nova Science Publ., pp. 89-102

Biloa E., 2011. Le français parlé et écrit en Afrique : Bilan et perspectives. Saarbrucken, Editions universiataires europeennes Publ. $532 \mathrm{p}$.

Djoum Nkwescheu A., 2000. Aspects prosodiques et phonématiques $d u$ français parlé au Cameroun. Grenoble, Université de Grenoble IIIStendhal Publ. 530 p.

Djoum Nkwescheu A., 2008. Les tendances fédératrices des déviations du Français camerounais de l'identité des processus linguistiques dans les changements diachroniques et géographiques. Le français en Afrique, no. 23, pp. 167-198.

Féral de C., 1991. Norme endogène du français au Cameroun. Bulletin du Centre d'étude des plurilinguismes, no. 12 , pp. 65-71.

Feussi V., 2006. Une construction du français à DoualaCameroun. Tours, Université François Rabelais de Tours Publ. $717 \mathrm{p}$.

Fosso C. de F., 2004. Dynamique du français au Cameroun: problèmes sociolinguistiques et stylistiques, enjeux didactiques et glottopolitiques. Yaoundé, Presses universitaires d'Afrique. $270 \mathrm{p}$.

Mendo Ze G., 1990. Une crise dans les crises. Le français en Afrique noire camerounais où chaque groupe linguistique tient à son identité, l'État francophone. Le cas du Cameroun. Paris, ABC Publ. $380 \mathrm{p}$.

Zang Zang P., 1991. Le processus de dialectalisation du français en Afrique noire: le cas du Cameroun. Yaoundé, Université de Yaoundé I. $450 \mathrm{p}$. 


\section{МАТЕРИАЛЫ И СООБЩЕНИЯ}

Zang Zang P., 1998. Le français en Afrique: normes, tendances évolutives, dialectisation. Munchen, Lincom Europa Publ. 452 p.
Zang Zang P., 1999. Le phonétisme du français camerounais. Mendo Ze, ed. Le français langue africaine. Paris, Publisud, pp. 112-129.

\section{Information about the Author}

Yuliya S. Blazhevich, Candidate of Sciences (Philology), Associate Professor, Department of Foreign Languages and Professional Communication, Belgorod National Research University, Pobedy St., 85, 308015 Belgorod, Russia, blazhevich@bsu.edu.ru, https://orcid.org/0000-0002-6738-3515

\section{Информация об авторе}

Юлия Сергеевна Блажевич, кандидат филологических наук, доцент кафедры иностранных языков и профессиональной коммуникации, Белгородский национальный исследовательский университет, ул. Победы, 85, 308015 г. Белгород, Россия, blazhevich@bsu.edu.ru, https://orcid.org/0000-0002-6738-3515 